SOBRE
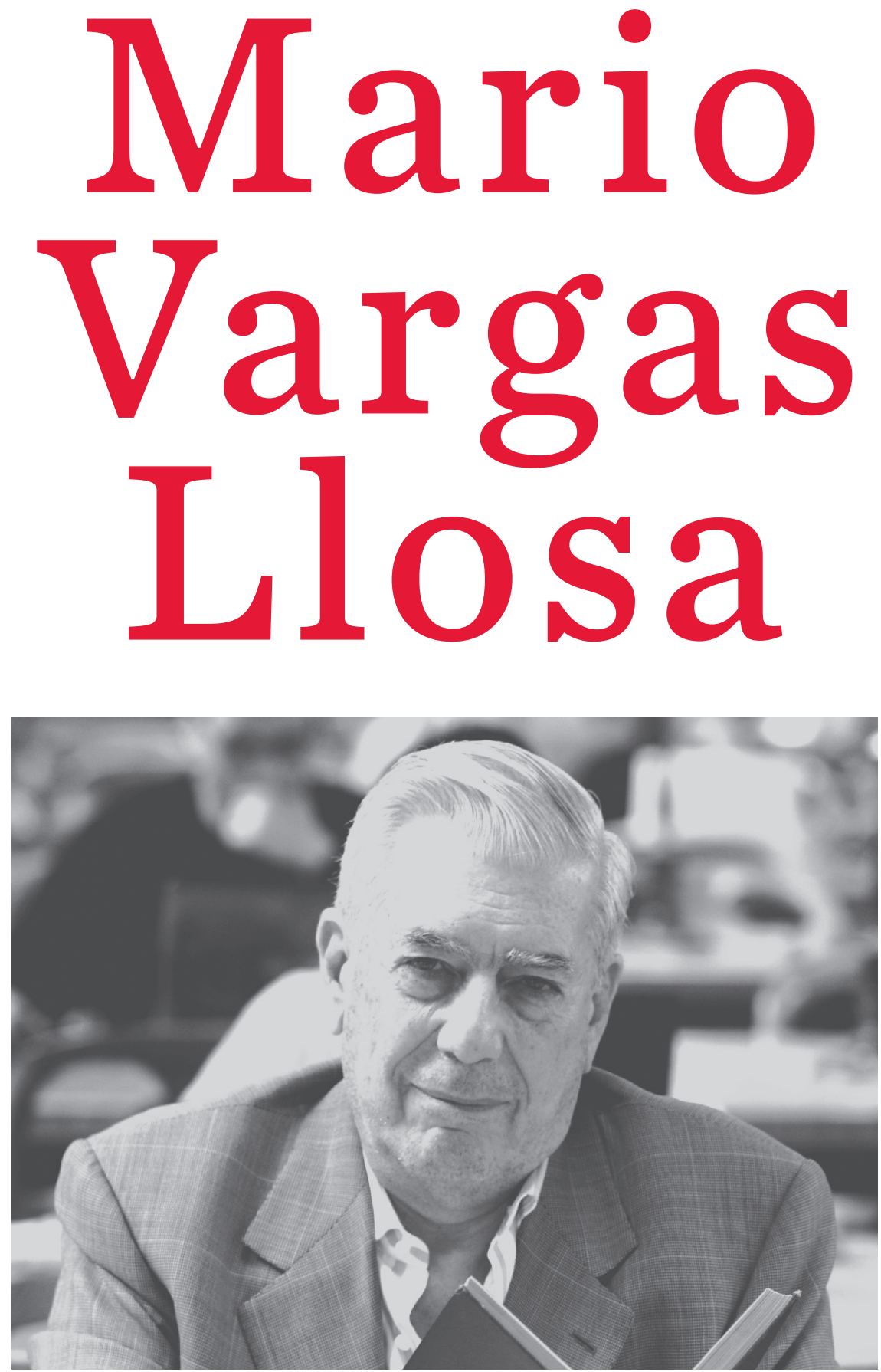

María Jesús Lorenzo-Modia, ed. 


\section{Sobre}

\section{Mario Vargas Llosa}

María Jesús Lorenzo-Modia (ed.)

A Coruña 2019

Universidade da Coruña

Servizo de Publicacións 


\section{Sobre Mario Vargas Llosa}

María Jesús Lorenzo-Modia (editora)

A Coruña, 2019

Universidade da Coruña, Servizo de Publicacións

ISBN: 978-84-9749-729-9 (formato impreso)

ISBN: 978-84-9749-730-5 (formato electrónico, DVD)

ISBN: 978-84-9749-731-2 (formato electrónico, repositorio de la UDC)

Depósito Legal: C 1383-2019

DOI: https:/doi.org/10.17979/spudc.9788497497312

(C) de la edición, Universidade da Coruña

(C) de los textos, los autores

(C) de la imagen de cubierta, Morgana Vargas Llosa

Doble página de guardas: El cielo de Arequipa el 28 de marzo de 1936. Fotografía cedida por Museos científicos, Ayuntamiento de A Coruña

Distribución editorial: <https://www.udc.gal/es/publicacions/distribucion>

Diseño de la cubierta: Julia Núñez Calo

Diseño de interior: Juan de la Fuente

Impresión: Lugami Artes Gráficas, Betanzos (España)

Printed in Spain

Este trabajo ha sido posible gracias al apoyo de la Universidade da Coruña (Vicerrectorado de Economía, Infraestructuras y Sostenibilidad, Campus Innova y Campus Sustentabilidade), MICINN (FEM2015-66937-P, PGC2018-093545-B-100) y de la Xunta de Galicia (Consellería de Cultura e Turismo y Consellería de Educación, Universidade e Formación Profesional, ED431D2017-17). 


\section{ÍNDICE}

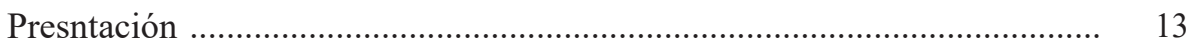

María Jesús LoRenzo-Modia

"Mentiras que tienen apariencia de verdades" o la literatura según Vargas

Llosa

Mario Vargas Llosa

Vela de armas por una luchadora

JuAn CRUZ RUIZ

El padre, la madre y la inspiración

Marie-Madeleine Gladieu

Mario Vargas Llosa, la poesía y los poetas.

\section{EFRAÍN KRISTAL}

La ambigüedad en la narrativa de Mario Vargas Llosa y sus antecedentes en Faulkner, Mann y Borges.

Roy C. Boland OSEgueda

Un escritor del Sur: el anti-colonialismo en algunas novelas de Mario Vargas Llosa desde la perspectiva de J. M. Coetzee.

María ConCePción ReVERTE Bernal

Mario Vargas Llosa: crítica al nacionalismo y al patriotismo

María Jesús LoRenZo-Modia

Entrevista a Mario Vargas Llosa, 22/03/2019 


\title{
Un escritor del Sur: el anti-colonialismo en algunas novelas de Mario Vargas Llosa desde la perspectiva de J. M. Coetzee
}

\author{
Roy C. Boland Osegueda \\ Profesor emérito. The University of Sydney
}

\begin{abstract}
T M. Coetzee, el gran escritor sudafricano, reside en Australia desde . 2002, un año antes de que recibiera el Premio Nobel de Literatura. En la actualidad ejerce como catedrático honorario en el departamento de inglés de la Universidad de Adelaide, donde el Centro de Prácticas Creativas lleva su nombre. Ciudadano australiano desde 2010, hace varios años que Coetzee también mantiene una relación personal e intensa con Latinoamérica, con España y el español.

Mario Vargas Llosa ayudó a diseminar la obra y reputación de Coetzee en el mundo hispano, designándolo en "¡Cuidado con Elizabeth Costello!”, una reseña de su novela The Lives of Animals (1999), como "uno de los mejores novelistas vivos" por "su maestría y sutileza contando historias" (Obras completas XI, 300). En esta reseña también lo elogia como un ensayista y conferenciante "polémico y radical" que desarrolla "atrevidas y discutibles teorías" (300). Coetzee ha visitado diversos países en Latinoamérica, entre ellos Chile, donde existe un premio literario en su honor, además de México, Uruguay, Argentina y Brasil. Su simpatía por el español es tal que en sus últimas tres novelas - la trilogía compuesta por
\end{abstract}

Boland Osegueda, Roy C. "Un escritor del Sur. El anti-colonialismo en algunas novelas de Mario Vargas Llosa desde la perspectiva de J.M. Coetzee". Lorenzo-Modia, María Jesús, ed. Sobre Mario Vargas Llosa. A Coruña: Servizo de Publicacións da Universidade da Coruña, 2019, pp. 69-80.

DOI: https://doi.org/10.17979/spudc.9788497497312.069 
La infancia de Jesús (2013), Los días de Jesús en la escuela (2017) y La muerte de Jesús (2019), los personajes viven en un mundo platónico donde se habla la lengua de Cervantes y el protagonista, un niño llamado Jesús, interpreta el mundo a través de Don Quijote de la Mancha. Además, en "La anciana de los gatos", un relato en Siete cuentos morales (2018), una protagonista recurrente y memorable en el mundo ficticio de Coetzee llamada Elizabeth Costello se retira a esperar la muerte en San Juan Obispo, un pueblo perdido de la meseta castellana donde se habla un español antiguo y los campesinos se atienen a una dieta del siglo XIX. Aquí, esta novelista australiana, una fanática defensora de los derechos de los animales, vive contenta y satisfecha, rodeada de una "verdadera plaga de gatos" (75) y acompañada por "el idiota del pueblo" (82). A través de estos dos alter egos —el pequeño Jesús y la viejita Elizabeth Costello- Coetzee transmite a los lectores su creciente fervor por el español y la cultura hispana.

Entre 2015 y 2018, Coetzee ocupó una cátedra personal en la Universidad de San Martín en Buenos Aires (UNSAM), donde presidió un programa de estudios titulado "Las Literaturas del Sur", con un enfoque especial sobre África del Sur, Australia y Argentina. Durante este período Coetzee desarrolló una teoría sobre el Sur y sus literaturas —una teoría lúcida y coherente, aunque sin duda también discutible. En una serie de conversaciones públicas en España, Argentina y Colombia con su editora en español, Soledad Constantini, además de alguna que otra conferencia o entrevista, Coetzee reconoce que su teoría es "heterodoxa", ya que "nada contra la corriente, que fluye desde el Norte al Sur"; esperar que fluya al revés es una ilusión, así que Coetzee aboga por "un diálogo Sur-Sur" (Sessarego)․․ Sea esto como fuere, la teoría de Coetzee sobre el Sur y sus escritores sirve para arrojar luz sobre una dimensión poco conocida y no muy estudiada en las novelas de Vargas Llosa: la relación Norte-Sur, el colonialismo y el anticolonialismo ${ }^{2}$.

1 Varias de las conversaciones con Constanini están disponibles en la red. Algunas de las más relevantes están incluidas en la Bibliografía. El único texto de Coetzee publicado sobre su teoría del Sur y su literatura es "Literature of the South: Introductory Remarks".

2 Algunos críticos han enfocado obras de Vargas Llosa desde una perspectiva poscolonial. Véase al respecto Susanne Cadera, "Mario Vargas Llosa y la temática poscolonial" y H.C.Weldt-Basson, "El sueño del celta: Postcolonial Vargas Llosa". Para un enfoque anticolonial, véase Roy Boland, "Anticolonialism and Testimony: Key Themes and Ideas in El sueño del celta". 
Resumo primero el argumento de Coetzee. Entrando en diálogo con las ideas de la socióloga australiana Raewyn Connell en su influyente libro Southern Theory (2007), el escritor sudafricano descarta el concepto geopolítico del "Sur Global" por considerarlo una odiosa invención de las potencias del Norte, o sea los Estados Unidos, Inglaterra y algunas naciones europeas, que suelen mirar el Sur como el "otro", un tipo de versión primitiva y atrasada de sí mismos ${ }^{3}$. Coetzee postula, en cambio, una visión del "verdadero Sur", un conglomerado de países, entre ellos Argentina, África del Sur y Australia, que, a pesar de la distancia entre ellos y de las diferencias lingüísticas, raciales o económicas, están hermanados por una serie de afinidades relacionadas con la naturaleza, la historia y la cultura. Según Coetzee, la afinidad más destacada entre los países del verdadero Sur es una larga y complicada historia de colonialismo, durante la cual algunas potencias del Norte han intentado, y casi siempre logrado, imponer una hegemonía política, económica o cultural. A este respecto, hay que recordar que muchos países del Sur, en África, Latinoamérica, Asia, Oriente y la zona austral del Pacífico, han sido el blanco de designios imperiales. Coetzee es especialmente duro con los Estados Unidos, al que critica por su inquebrantable convicción de que su sistema político, su cultura y su modo de vida están destinados a conquistar el mundo (Constantini, "J.M.Coetzee: las literaturas").

Por otra parte, Coetzee emplea su experiencia personal como escritor sudafricano para extender su tesis del colonialismo al mundo editorial (Constantini "J.M.Coetzee: las literaturas"). La primera lengua de Coetzee es el Afrikaáns, pero muy pronto se dio cuenta de que para poder realizar sus ambiciones literarias, no le quedaba otra opción que escribir en inglés. Con el tiempo, sus novelas tuvieron éxito, fueron publicadas por editoriales en Londres y Nueva York, traducidas al inglés y distribuidas internacionalmente desde estas dos capitales del mundo editorial anglófono. En este sentido, Coetzee se solidariza con los "escritores del sur" que escriben en español y quienes, al ser traducidos al inglés y distribuidos desde Londres o Nueva York, adquieren la etiqueta de "international writers" (escrito-

3 Véase al respecto James Halford, "Southern Conversations: J.M. Coetzee in Buenos Aires". Además de dilucidar la influencia de Raewynn Connell sobre Coetzee, Halford analiza una serie de textos australianos a la luz del concepto de las literaturas del Sur de Coetzee. 
res internacionales). Con sorna, Coetzee comenta que no sabe de ningún escritor de Estados Unidos o Inglaterra identificado como un "international writer" (ciertamente no contemporáneos como Martin Amis, Zadie Smith, Paul Auster, o Margaret Atwood, aunque ésta nació en Canadá). Además, Coetzee aclara que ya no se siente cómodo con el inglés, "a nivel personal, filosófico e incluso a nivel político" (Sigüenza), pues ésta es una lengua que parece tener imbricada un complejo de superioridad por estar convirtiéndose en idioma mundial a través de la globalización. Como protesta contra lo que él considera un tipo de colonialismo cultural, Coetzee ha insistido en publicar en español sus dos libros más recientes, Siete cuentos morales y La muerte de Jesús, y no se ha anunciado todavía cuando serán publicados en inglés. Cabría preguntarse hasta qué punto el argumento de Coetzee sobre el estatus de un "international writer" está condicionado por ser oriundo de África del Sur, una ex-colonia inglesa, y además, por residir ahora en otra ex-colonia inglesa, Australia, un país rico del primer mundo pero culturalmente en la periferia del mundo anglófono. Coetzee se refiere a los australianos como "chicos provincianos de Gran Bretaña o Estados Unidos" ("Clarin").

Ahora bien: en términos generales, como novelista, Mario Vargas Llosa encaja con la idea del "escritor del Sur" acuñada por Coetzee. Mario Vargas Llosa nació, se crio y se educó en el Perú, desde los estudios de primaria hasta adquirir la licenciatura en la Universidad de San Marcos, en Lima. Siempre, donde quiera que haya residido, ha mantenido una relación profunda y pasional con el Perú. La mayoría de sus novelas están ubicadas en este país, desde centros metropolitanos como Lima o Piura, provinciales como Talara o Chincha, o selváticos como Santa María de Nieva o el Putumayo, y aun cuando el ambiente no es peruano, exhalan peruanidad. Están escritas en el español de un autor peruano que sabe adaptar su lenguaje a las circunstancias de cada novela, tal como ocurre en $\mathrm{La}$ fiesta del chivo (2000), que se ambienta en la República Dominicana. Por ejemplo, solamente en esta novela aparece el extraño vocablo "suapeando" (93), cuya etimología y significado hay que buscar en un diccionario de dominicanismos ${ }^{4}$.

4 "Suapear" significa limpiar el suelo utilizando un "suape", un artefacto para fregar los suelos sin necesidad de arrodillarse. El "suape" consiste en un mango largo con un manojo de tiras hechas de un tejido, lo que en el español de España se conoce habitualmente como "fregona", o, en ocasiones, "mopa". 
Sin embargo, hay una discrepancia entre Vargas Llosa y Coetzee en cuanto a la noción del "international writer", que, como hemos visto, tiene una connotación negativa o despectiva para Coetzee. Desde su primera novela, La ciudad y los perros (1963), hasta su más reciente, Cinco esquinas (2016), todas las novelas de Vargas Llosa están publicadas por grandes editoriales en España y desde allí llegan al resto del mundo hispano, lo cual es lógico por la falta de editoriales nacionales de distribución internacional en el Perú. Después son traducidas y distribuidas en el mundo anglófono desde Inglaterra y Estados Unidos: ciertamente así llegan a la distante Australia, donde Vargas Llosa es bastante leído y reseñado en los medios culturales. Vargas Llosa nunca se ha pronunciado con resentimiento por ser publicado en España. Tampoco le incomoda ser traducido al inglés y distribuido internacionalmente desde Inglaterra y Estados Unidos. Todo lo contrario: como otros escritores latinoamericanos - Carlos Fuentes, García Márquez, Isabel Allende o Luisa Valenzuela, y al igual que escritores españoles como Javier Marías, Manuel Rivas o Alfredo Conde, Vargas Llosa se siente complacido de que sus obras lleguen de esta forma a lectores más allá del mundo hispano. De hecho, ha declarado que la primera vez que se sintió escritor de verdad fue cuando su novela La ciudad y los perros fue traducida a diez lenguas distintas. En sus propias palabras, “¡No podía creerlo!” (Faginas).

Por otra parte, la visión del Sur de Coetzee es muy aplicable al Perú y a su representación novelesca por Vargas Llosa. Como en el caso de Argentina, África del Sur y Australia, para el Perú el colonialismo ha sido un trauma histórico que Vargas Llosa recrea en algunas de sus historias más lacerantes. Pero mientras que en su argumento Coetzee subraya una cara del colonialismo - la externa - Vargas Llosa muestra dos caras en sus novelas, la externa y la interna. Resumiendo: el colonialismo externo se refiere a la imposición de la hegemonía sobre otro país o región por potencias extranjeras, ya sea por una nación más fuerte y rica, una corporación económica extranjera, o instituciones religiosas o culturales foráneas. En cambio, el colonialismo interno tiene que ver con las relaciones de poder entre los amos y los subalternos dentro de una nación o región: por ejemplo, los militares y los civiles, los ricos y los pobres, los blancos y los negros, los mestizos y los indígenas, los hombres y las mujeres, entre otras dicotomías en torno a la desigualdad o injusticia ${ }^{5}$.

5 Sobre los diferentes tipos de colonialismo, ver Nancy Shoemaker, "A Typology of Colonialism". 
La novela paradigmática que muestra estas dos caras del colonialismo es El sueño del celta, publicada en 2010, poco después de que Vargas Llosa recibiera el Nobel. Esta novela histórica encaja perfectamente con las palabras de la Academia Sueca honrando a Vargas Llosa por su "cartografía de las estructuras del poder y sus mordaces imágenes de la resistencia, rebelión y derrota del individuo" ("The Novel Prize"). La portada de la primera edición de Alfaguara de El sueño del celta constituye una prefiguración gráfica del contenido de la novela. El mapamundi está superpuesto al perfil del protagonista, Roger Casement (1864-1916), un legendario pero malhadado irlandés que, a finales del siglo XIX y principios del XX, luchó literalmente hasta la muerte en una cruzada por los derechos humanos en tres puntos geográficos indicados por las grandes manchas en rojo de la portada: Irlanda (arriba), la Amazonía (abajo a la izquierda) y el Congo (abajo a la derecha). Obviamente, el rojo simboliza la sangre derramada de los pueblos brutalmente colonizados y sometidos a la servidumbre o esclavitud. La cara externa del colonialismo está representada por el rey Leopoldo II de Bélgica en el Congo y por la corona inglesa en Irlanda, mientras que la cara interna aparece encarnada en la Amazonía por un crio1lo peruano, Julio César Arana, un barón del caucho que se comporta como un sátrapa ${ }^{6}$. En las partes de la novela ubicadas en África o la Amazonía, los miles de negros e indios no tienen nombre: su identidad individual se oblitera en un alud de cuerpos destrozados: nalgas y espaldas rajadas por el látigo, caras con cicatrices, manos o piernas cercenadas, troncos decapitados. Las escenas de conquista, explotación, persecución y muerte evocan los Desastres de la guerra de Goya y el Guernica de Picasso. Aunque en la ficción de Vargas Llosa no hay dogmatismo, didacticismo o sesgos ideológicos, de El sueño del Celta, como de otras de sus novelas, se puede desprender una contundente lectura anticolonialista. Ciertamente, las víctimas del colonialismo reclaman la simpatía y solidaridad de los lectores, y los victimarios su desprecio, asco o furia.

En otra novela de Vargas Llosa, Historia de Mayta - cuya fecha de publicación, no por casualidad, coincide con el título de 1984, la famosa obra contra el totalitarismo de George Orwell, el protagonista, Alejandro

6 Para estudios históricos de Leopoldo II en el Congo, el colonialism inglés en Irlanda y el imperio del caucho de Julio Arana en la Amazonía, véanse respectivamente Adam Hochschild, King Leopold's Ghost, Thomas Kenneally, The Great Shame, y Ovidio Lagos, Arana. Rey del caucho. 
Mayta, achaca los males del Perú a los que él describe como "los que tienen la sartén por el mango", entre ellos los militares, los políticos, los curas, los dueños de la tierra, los ricos y los "terrucos" (78). Como Mayta es un revolucionario caricaturesco que falla en todo lo que pretende y un trotskista intransigente, su interpretación de la historia y realidad peruanas es tendenciosa. Sin embargo, Mayta será un ideólogo trasnochado, pero en algunos aspectos su diagnosis coincide con la realidad ficticia de Vargas Llosa, y, si salimos de la ficción, con la realidad histórica. Por ejemplo, los que Mayta acusa de tener la sartén por el mango, son, en su mayoría, peruanos de la misma calaña que aquéllos que en las novelas de Vargas Llosa convierten el Perú en una colonia interna. Así, en Conversación en la Catedral (1969), el general Odría y sus colaboradores en el ejército y la oligarquía imponen un régimen dictatorial que se asemeja a un estado cuartel. Otro militar arquetípico es el Coronel Mindreau en ¿Quién mató a Palomino Molero? (1986), un déspota que regenta la ciudad de Talara como si fuera un feudo personal. En La casa verde (1966), un gángster llamado Julio Réategui se autoproclama gobernador de un trozo de la Amazonía, y con la protección de los militares, la colaboración de los oligarcas limeños y el apoyo tácito de la iglesia, lanza una campaña de terror contra los indígenas de la zona e impone un monopolio implacable y sangriento sobre la industria cauchera.

Quizá sea en la novela más reciente de Vargas Llosa, Cinco esquinas (2016), donde esté representada la colonia interna más lúgubre y asfixiante. La preside el Doctor Vladimir Montesinos, el "amo y señor del Perú" (228), un tipo de Drácula criollo que chupa sangre y dinero y maneja las palancas de su poder omnipotente en las tinieblas. La oscuridad y el color negro son motivos recurrentes: en palabras de Montesinos, "Sólo en la noche puedo concentrarme en lo importante" (232). Y, otra vez, citando sus propias palabras, lo importante para este monstruo es "investigar" y "joder" (243) a los que se ponen en su camino: un camino del que emana un tufo a excremento, sudor, sangre, orines y semen seco, como si se tratara de una truculenta película de terror. Esta pestilencia física refleja la putrefacción política y moral del régimen de Montesinos y su presunto jefe, el Presidente Fujimori: un régimen basado en el miedo a terminar como unos militares desleales a quien Montesinos les hizo inyectar el virus del sida. En "Herederos de Nechaiev", una reseña de Los demonios, de Dostoyevski, Vargas Llosa elogia al gran autor ruso por la genialidad con que escarba en 
los fondos tortuosos e indómitos del mal. Es esto exactamente lo que lleva a cabo Vargas Llosa en su retrato del Doctor Montesinos, a quien alguien describe como "ese genio del mal" (244).

En su lista de los que tienen la sartén por el mango, Alejandro Mayta incluye a los "terrucos". Aunque Historia de Mayta se desarrolla en 1958, los "terrucos" se pueden tomar como una referencia a posteriori a Sendero Luminoso, cuya pretensión en otra novela, Lituma en los Andes (1993), es imponer, primero en el Perú y luego en el mundo entero, una colonia totalitaria donde la noción de la libertad ha sido abolida. Los ecos de 1984 de Orwell resuenan en Lituma en los Andes. El gurú criollo, el Camarada Gonzalo, es el Big Brother (el Gran Hermano), y a través de sus sicarios senderistas vigila y controla implacablemente las palabras, los pensamientos y los actos. Es decir, todos los aspectos de la vida de sus súbditos.

En resumidas cuentas, en las novelas de Vargas Llosa los poderosos hablan con lo que en ¿Quién mató a Palomino Molero? se describe como "la voz del amo" (68), y los que no la obedecen corren el riesgo de terminar como el cacique Jum en La casa verde, humillado, rapado y torturado, o peor todavía, crucificado con un palo en el trasero como Palomino Molero, el desdichado cantante de boleros en la novela epónima. Ni los animales están a salvo: en Lituma en los Andes un rebaño de vicuñas es masacrado porque los "terrucos" consideran a las hermosas e inofensivas criaturas cómplices del imperialismo internacional.

En su diatriba contra los que han reducido el Perú a un estado de dependencia, Alejandro Mayta apunta también a los marines, quizá el símbolo por antonomasia del poderío de los Estados Unidos. En las novelas de Vargas Llosa hay situaciones en que asoma la sombra ominosa del Gigante del Norte, que, cuando lo considera necesario, invade países del Sur, ejerce presiones políticas e impone su cultura. Además, tampoco vacila en comprar con dólares a colaboradores internos como el Doctor Vladimiro Montesinos, quien en Cinco Esquinas "espiaba y pasaba secretos militares a la CIA" (230). Pero es sin duda en La fiesta del chivo donde los Estados Unidos juega el papel más nocivo. El dictador Trujillo es retratado como una creación monstruosa de los Estados Unidos, un tipo de Frankenstein caribeño. Este sátrapa asesino y ladrón se ufana de ser un ex-marine, un título que significa casi tanto para él como el de Benefactor de la Patria. Trujillo recuerda que fue durante la ocupación militar de la República Dominicana por los "gringos" que ingresó en los marines, quienes le incul- 
caron la importancia de la disciplina y la sangre fría, dos cualidades de las que se ha valido para subyugar a sangre y fuego a los dominicanos. Trujillo no tiene reparos en reconocer que, con tal de que los siguiera untando con dólares y cheques, una retahíla de políticos, periodistas y abogados de Estados Unidos estaban dispuestos a hacer la vista gorda ante sus fechorías dentro y fuera del país. En un artículo reciente, "Largo camino hacia la libertad", Vargas Llosa cita un famoso refrán, "Mira con quién andas y te diré quién eres", que resume la relación íntima entre Trujillo y los Estados Unidos durante la mayor parte de sus treinta y un años de dictadura.

De hecho, la prepotencia de los Estados Unidos se insinúa desde la primera novela. En La ciudad y los perros, un ministro del gobierno y altos cargos militares actúan con un servilismo colonial ante la embajadora norteamericana, dirigiéndose a ella como "ilustrísima", "excelentísima", "dignísima", y agradeciéndole su "infinita bondad" (72-80). La intención es clara: si los peruanos se comportan bien, la embajadora los tratará con generosidad. Luego, en Conversación en la Catedral, los políticos y los militares saben que su continuidad en el poder depende de los Estados Unidos. Así lo da a entender Cayo Bermúdez, el director de seguridad del dictador Odría: "La fuerza del régimen era el apoyo de los grupos que cuentan...Y...ni los gringos nos quieren ya" (429). Y en ¿Quién mató a Palomino Molero? una sola imagen basta para comunicar el poder económico de los Estados Unidos: la International Petroleum Company ocupa un promontorio rocoso en Talara, el punto geográfico más alto desde donde los "gringos" pueden vigilar y controlar los asuntos en su colonia.

Sin embargo, el colonialismo norteamericano no sólo ejerce influencia sobre la política y la economía del Perú, sino también sobre su cultura. Antonio de Nebrija profetizó hace más de cinco siglos que la lengua sería un arma poderosa del imperio español, y esta profecía se cumple en el mundo ficticio de Vargas Llosa, pero con respecto a la colonización del Perú (y de otras partes de Latinoamérica) por el idioma inglés. Por ejemplo, en Conversación en la Catedral, hay personajes con apodos tan cursis como "Popeye" y la burguesía limeña se envenena con "hot dogs", "corn flakes", "panqueques" y "milk shakes". En La fiesta del chivo, la realidad histórica de un país invadido y ocupado por Uncle Sam dos veces en el siglo XX (1916-24 y 1965-66) está reflejada por la intrusión de anglicismos en cursiva como fellow travellers, sisters, joggers, lifting, braces, baby, hobby, dormitory o frases como "aerobics en el Fitness Centre". En 
Lituma en los Andes, este colonialismo lingüístico penetra hasta una región quechuahablante, donde se cuela un anglicismo chocante: "voy a tirar una luqueada" (de "look" en inglés). En una de las novelas más recientes de Vargas Llosa, El héroe discreto (2013), se cuelan corrupciones flagrantes del inglés como "lonche", "overols" y "shoppings", mientras que la expresión "estar azul" parece ser una traducción directa de "to feel blue" (sentirse triste o deprimido). En este sentido, las novelas de Vargas Llosa se hacen eco de la advertencia del profesor Porras Barrenechea en El hablador (1987): "los indígenas selváticos aprenderán probablemente a hablar inglés antes que español" (70). Para un Premio Nobel de Literatura que es miembro de la Academia Peruana de la Lengua y de la Real Academia Española, esta profecía tiene que ser profundamente alarmante.

\section{OBRAS CITADAS}

Boland, Roy. "Anti-colonialism and Testimony: Key Themes and Ideas in El sueño del celta by Mario Vargas Llosa". Quaderni Ibero Americani, Gennaio-Dicembre 2018, número 10, pp. 79-94.

Cadera, Susanne. "Mario Vargas Llosa y la temática poscolonial". Antípodas XXVII, 2016, pp. 49-61.

“Clarín en la Feria del Libro. Coetzee y la literatura de los países del sur”. 22/04/2016, https://www.clarin.com/cultura/coetzee-literatura-paises-sur_0_VkU9Ynme-. html.

Coetzee, J.M. Elizabeth Costello. Havill Secker, 2003.

Coetzee, J.M. "La anciana de los gatos". Siete cuentos morales. Traducción de Elena Marengo, Literatura Random House, 2018, pp. 65-87.

Coetzee, J.M. La infancia de Jesús. Traducción de Miguel Temprano García, Mondadori, 2013.

Coetzee, J.M. La muerte de Jesús. Traducción de Elena Marengo, El Hilo Dariadna/ Literatura Random House, 2019.

Coetzee, J.M. "Literatures of the South: Introductory Remarks". Literaturas del Sur. UNSAM, 2016.

Coetzee, J.M. Los días de Jesús en la escuela. Traducción de Javier Calvo, Literatura Random House, 2017.

Coetzee, J.M. Siete cuentos morales. Traducción de Elena Marengo, Literatura Random House.

Coetzee, J.M. The Schooldays of Jesus. Text, 2016. 
Coetzee, J.M. The Lives of Animals. Princeton University Press, 1999. ---. The Childhood of Jesus. Text, 2013.

Connell, Raewyn. Southern Theory. Allen and Unwin, 2007.

Constantini, Soledad. "In Conversation: J.M Coetzee with Soledad Constantini”. 30 May 2018, https://www.youtube.com/watch?v+4VNk-52t-YPM.

Constantini, Soledad. "J. M. Coetzee in Conversation with Soledad Constantini". Cartagena, Saturday 27 January 2018, https://www.hayfestival.com/p-13287-jmcoetzee-in-conversation-with-soledad-costantini.aspx?skinid=16.

Constantini, Soledad. “J. M. Coetzee: las literaturas del sur (inglés)”. 28 May 2018, https:/www.youtube.com/watch?V=DW!QRdJ9rDG.

Constantini, Soledad. "John Maxwell Coetzee Talks with Editor Soledad Constantini about His New Book Siete cuentos morales". Madrid, Spain, 26 May 2018, https://www.alamy.com/madrid-spain-26th-may-2018-south-african-literaturenobel-laureate-in-2003-john-maxwell-coetzee-talks-with-editor-soledadconstantini-unseen-about-his-new-book-siete-cuentos-morales-lit-seven-moralstories-in-madrid-spain-26-may-2018-credit-jpgandulefealamy-live-newsimage186474718.html.

Dostoyevski, Fiódor. Los demonios. Madrid: Alianza Editorial, 2011.

Faginas, Sandra. "Mario Vargas Llosa: Si no termino la novela, la novela acaba conmigo". La Voz de Galicia, 30-03-2019, https://www. lavozdegalicia.es/noticia/fugas/2019/03/29/termino-novela-novela-acabaconmigo/0003_201903SF29P1991.htm.

Halford, James. "Southern Conversations: J. M. Coetzee in Buenos Aires". Sydney Review of Books, 28 February 2017, https://sydneyreviewofbooks.com/ southern-conversations-j-m-coetzee-in-buenos-aires.

Hochschild, Adam. King Leopold's Ghost. Mariner's Ghost, 1998.

Kenneally, Thomas. The Great Shame. Random House Australia, 1999.

Lagos, Ovidio. Arana. Rey del caucho. Emecé Editores, 2005.

Nebrija, Antonio de. Gramática de la lengua castellana. 1492. Edición de Antonio Quilis, Editora Nacional, 1981.

Orwell, George. 1984. Barcelona: Debolsillo, 2018.

Sessarego, Jéssica. "Trascender las fronteras del sur. Entrevista con J.M. Coetzee". Traducción de Jimena Reides. Revista Transas. Letras y Artes de América Latina, 6 de octubre de 2016, http://www.revistatransas.com/2016/10/06/ trascender-las-fronteras-del-sur-entrevista-con-j-m-coetzee.

Shoemaker, Nancy. "A Typology of Colonialism”. Perspectives on History, October 2015. https://www.historians.org/publications-and-directories/perspectives-on -history/october-2015-a-typology-of-colonialism. 
Sigüenza, Carme, "Coetzee: Tengo reservas con el inglés a nivel personal, filosófico y politico". EFE, Madrid, 26 mayo 2018, https:/www.efe.com/efe/espana/ cultura/coetzee-tengo-reservas-con-el-ingles-a-nivel-personal-filosofico-ypolitico/10005-3628941.

“The Nobel Prize in Literature 2010". Nobelprize.org. Nobel Media AB, 2014, https:// www.nobelprize.org/prizes/literature/2010/summary.

Vargas Llosa, Mario. Cinco esquinas. Alfaguara, 2016.

Vargas Llosa, Mario. Conversación en La Catedral. Seix Barral, 1969.

Vargas Llosa, Mario. “¡Cuidado con Elizabeth Costello!”. Obras Completas, vol. XI. Piedra de toque III (2000-2012), pp. 300-305.

Vargas Llosa, Mario. El hablador. Seix Barral, 1987.

Vargas Llosa, Mario. El héroe discreto. Alfaguara, 2013.

Vargas Llosa, Mario. "Herederos de Nechaiev". El País, 17 de febrero de 2019, https://elpais.com/elpais/2019/02/14/opinion/1550164875_746383.html.

Vargas Llosa, Mario. Historia de Mayta. Seix Barral, 1984.

Vargas Llosa, Mario. La ciudad y los perros. Seix Barral, 1963.

Vargas Llosa, Mario. La casa verde. Seix Barral, 1966.

Vargas Llosa, Mario. La fiesta del chivo. Alfaguara, 2000.

Vargas Llosa, Mario. "Largo camino hacia la libertad”. El País, 3 Febrero 2019, https:/elpais.com/elpais/2019/02/01/opinion/1549036512_989959.html.

Vargas Llosa, Mario. Lituma en los Andes. Seix Barral, 1993.

Vargas Llosa, Mario.¿Quién mató a Palomino Molero? Seix Barral, 1986.

Weldt-Basson, Helene Carol. "El sueño del celta. Postcolonial Vargas Llosa". Redefining Latin American Historical Fiction: The Impact of Feminism and Postcolonialism. Edited by Helene Carol Weldt-Basson, Palgrave MacMillan, 2013, pp. 231-247. 